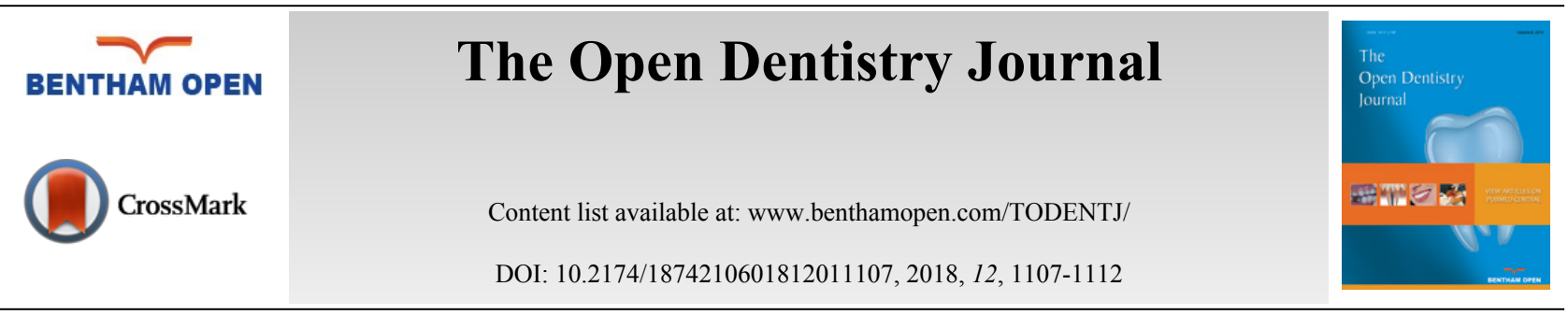

RESEARCH ARTICLE

\title{
Oral Rehabilitation of Patients with Ameloblastoma of the Mandible. Clinical Results in Three Patients with Different Bone Reconstruction Techniques
}

\author{
Shiva Raoufi-Danner ${ }^{1, *}$, Sterwin Carl $^{2}$ and Abtahi Jahan ${ }^{1}$ \\ ${ }^{I}$ Department of Oral and Maxillofacial Surgery, Linköping University Hospital, SE-581 85 Linköping, Sweden \\ ${ }^{2}$ Department of Oral and Maxillofacial Surgery, Ryhov Hospital, SE-551 85 Jönköping, Sweden
}

\section{Abstract:}

\section{Background:}

Ameloblastoma is the second most common odontogenic tumor. It shows a locally aggressive behavior, with a high level of recurrence. Wide resection of the jaw is recommended for treatment of ameloblastoma. However, radical surgery causes an abnormal mandibular movement, facial asymmetry, and masticatory dysfunction.

\section{Methods:}

Three cases of different types of ameloblastoma is presented, with different reconstruction techniques including Non-Vascularized Bone Graft (NVBG), Osteocutaneous Fibula Free Flap (OFFF), and Deep Circumflex Iliac Artery flap (DCIA).

\section{Results:}

In all three cases the tumor site was successfully reconstructed to obtain very good esthetic results as well as functional oral rehabilitation with implants and fixed prosthetics for optimal masticatory function.

\section{Conclusion:}

For reconstruction of the mandible, we prefer bone grafts from the iliac crest. The natural curvature and variable bone height offer a very good reconstruction of the defect.

Keywords: Ameloblastoma, Oral tumour, Benign tumour, Neoplasm of the jaw, Mandible, Computed Tomography (CT).

\section{INTRODUCTION}

Ameloblastomas represent approximately 1\% of all tumours and cysts of the maxilla and mandible, and $10 \%$ of all odontogenic mandibular tumours. In the maxillofacial region, the most common site of ameloblastomas is the angle and the body of the mandible. Clinically, these tumours are characterized by slow growth and painless symptoms, which may delay an early diagnosis and cause facial deformity, increased tooth mobility, and ulceration of the oral mucosa [1]. Ameloblastomas have been reported in both sexes and have been diagnosed in patients with a wide range of ages (20-50 years) [2]. The etiology of ameloblastoma is not understood, but according to the World Health Organization (WHO 2005), the ameloblastoma is derived from an odontogenic epithelial origin [3]. Causes may include injury to the mouth or jaw, infections of the teeth or gums, or inflammation of these same areas. Recent studies imply that there may be a host-response factor of periodontal disease that could trigger the neoplasm [4].

\footnotetext{
* Address Correspondence to this author at the Department of Oral and Maxillofacial Surgery, Linköping University Hospital, SE-581 85 Linköping, Sweden; Tel: +46101038566; E-mail: shiva.raoufi-danner@regionostergotland.se
} 
It has been realized for some years that ameloblastomas occur rather frequently in Africans [3]. Moreover, in black African countries, these lesions tend to occur in relatively young patients compared to those in white Africans, Europeans, and Asians [4].

Radiographically, ameloblastoma appears either unilocular or multilocular. Although the structure of these lesions can be detected on panoramic radiographs, Computed Tomography (CT) is to be preferred, due to the helpfulness of this imaging technique in determining the contours of the lesion, expansion of buccal and lingual cortical bones, resorption of adjacent teeth, and its extension into soft tissue [4]. Compared to CT, Magnetic Resonance Imaging (MRI) is slightly superior for establishing the exact extent of advanced maxillary ameloblastoma and the invasion of tumor mass into adjacent soft tissue [5].

The recommended treatment for ameloblastoma is surgical resection of tumour with safety margins of 1-2 cm, due to its aggressive recurrence rate $[6,7]$. Defect or discontinuity of the alveolar ridge of the mandible can be restored by different reconstruction flap techniques. The aim of this article is to present three cases of ameloblastoma, from diagnosis to rehabilitation, reconstructed with different flap techniques. The rationale of the study is to obtain the natural curvature and height of the mandible in order to rehabilitate a good functional occlusion for the patient.

\section{REPORTS OF CASES}

\subsection{Case 1}

A 54-year-old healthy Caucasian man was referred to the Department of Oral and Maxillofacial Surgery, Linköping University Hospital, in March 2005, due to the finding of a multilobulated cystic lesion in a routine panoramic radiograph at the left side of the mandible, with extension of the lesion from corpus mandible to ramus mandible (Fig. 1a). A biopsy was taken and the histological findings were consistent with ameloblastoma. There were no signs of malignancy. The patient underwent surgical removal of the mandible, including the tumor, with resection margin from tooth 36 to the anterior border of the ramus mandible. The pre-operative height and width of the mandible in region 36 was $26 \mathrm{~mm}$ and $13 \mathrm{~mm}$. The defect was immediately reconstructed by Deep Circumflex Iliac Artery flap (DCIA) with a bone piece of $6 \times 2.4 \mathrm{~cm}$ (Fig. 1b). The post-operative reconstructed site had an increase in both height and width to 29 $\mathrm{mm}$ and $15 \mathrm{~mm}$. After a healing period of one year, some resorption of the bone had occurred, but three implants (Microthread $^{\circledR}$ conical; Astra Tech AB, Mölndal, Sweden; $4.5 \mathrm{~mm}$ in diameter and $11 \mathrm{~mm}$ in length) were inserted at the left side of the mandible in a two-step fashion without complication. Six months later, the bridge was connected by the referring dentist and the patient could start using his new teeth (Figs. 1c \& d). No recurrence of the tumour was seen at 5-year follow-up.
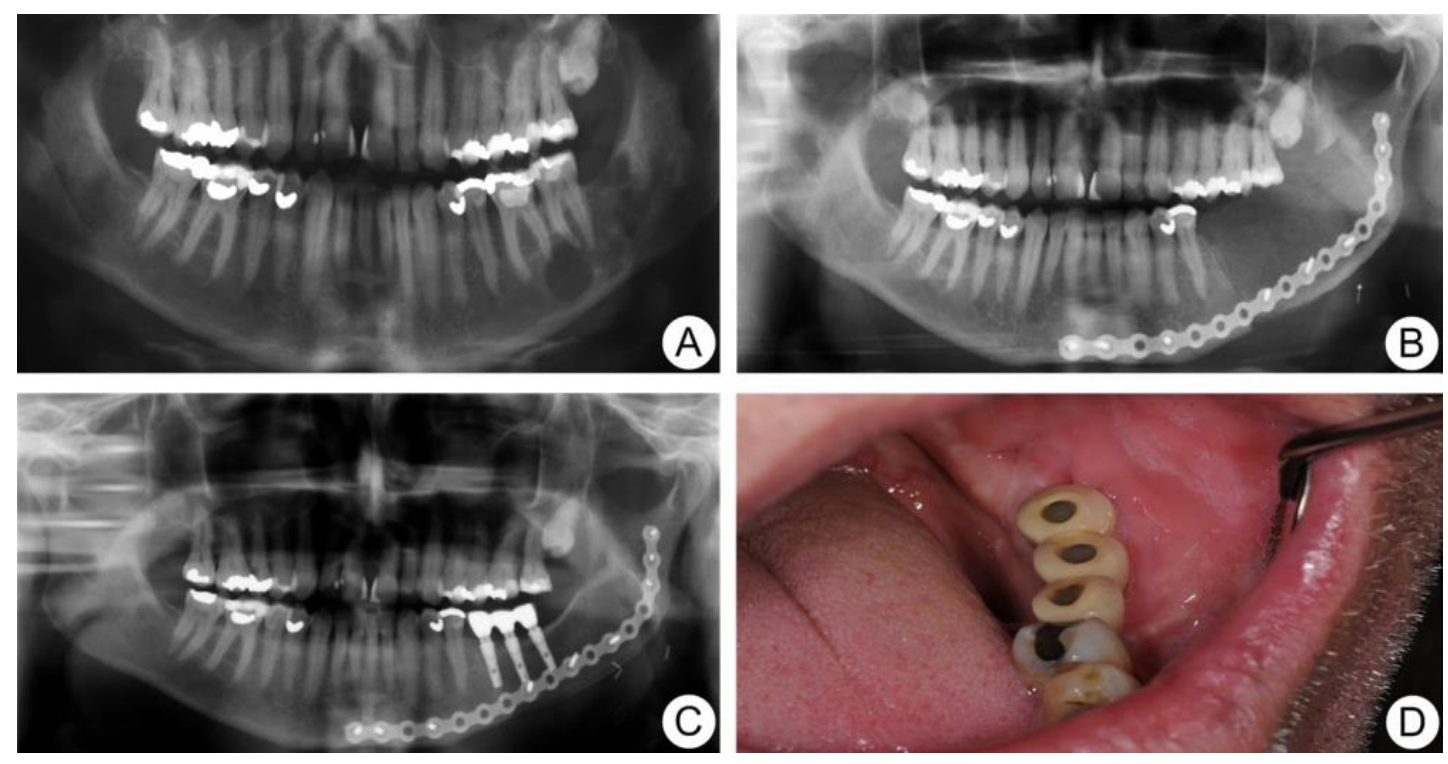

Fig. (1). Case 1. A. Panoramic radiograph from a patient with a multicystic lesion at the left side of the mandible. B. Postoperative panoramic radiograph obtained 3 months after reconstruction with DCIA. C-D. Postoperative panoramic radiograph after clinical photographs at 18 months after surgery and installation of implant-supported bridge. 


\subsection{Case 2}

A 42-year-old man of central African descent was referred to the Department of Oral and Maxillofacial Surgery, Umeå University Hospital, for a fast-growing mass at the right side of the facial skeleton in 2005 (Fig. 2a). Intraoral biopsy revealed histological features of ameloblastic carcinoma. The patient underwent hemi-mandibulectomy and the mandible was reconstructed with a free vascularized fibular transplant at Umeå University Hospital, Sweden. A postoperative CT-scan 3D-model showed complete healing of the fibula flap (Fig. 2b). In 2006, the patient was referred to the Department of Oral and Maxillofacial Surgery, Linköping University Hospital, Sweden for implant-supported rehabilitation of the right mandible. The bone height of the mandible was around $20 \mathrm{~mm}$ and deemed inadequate to receive an implant-supported bridge (Figs. 2b \& c), the width however, of circa $12 \mathrm{~mm}$ was sufficient. Thus, we decided to extend the bone tissue in a vertical direction with distraction-osteoneogenesis technique. Buccal and lingual plate horizontal corticotomy was performed and the distraction device was placed perpendicular to the corticotomy (Fig. 2d).
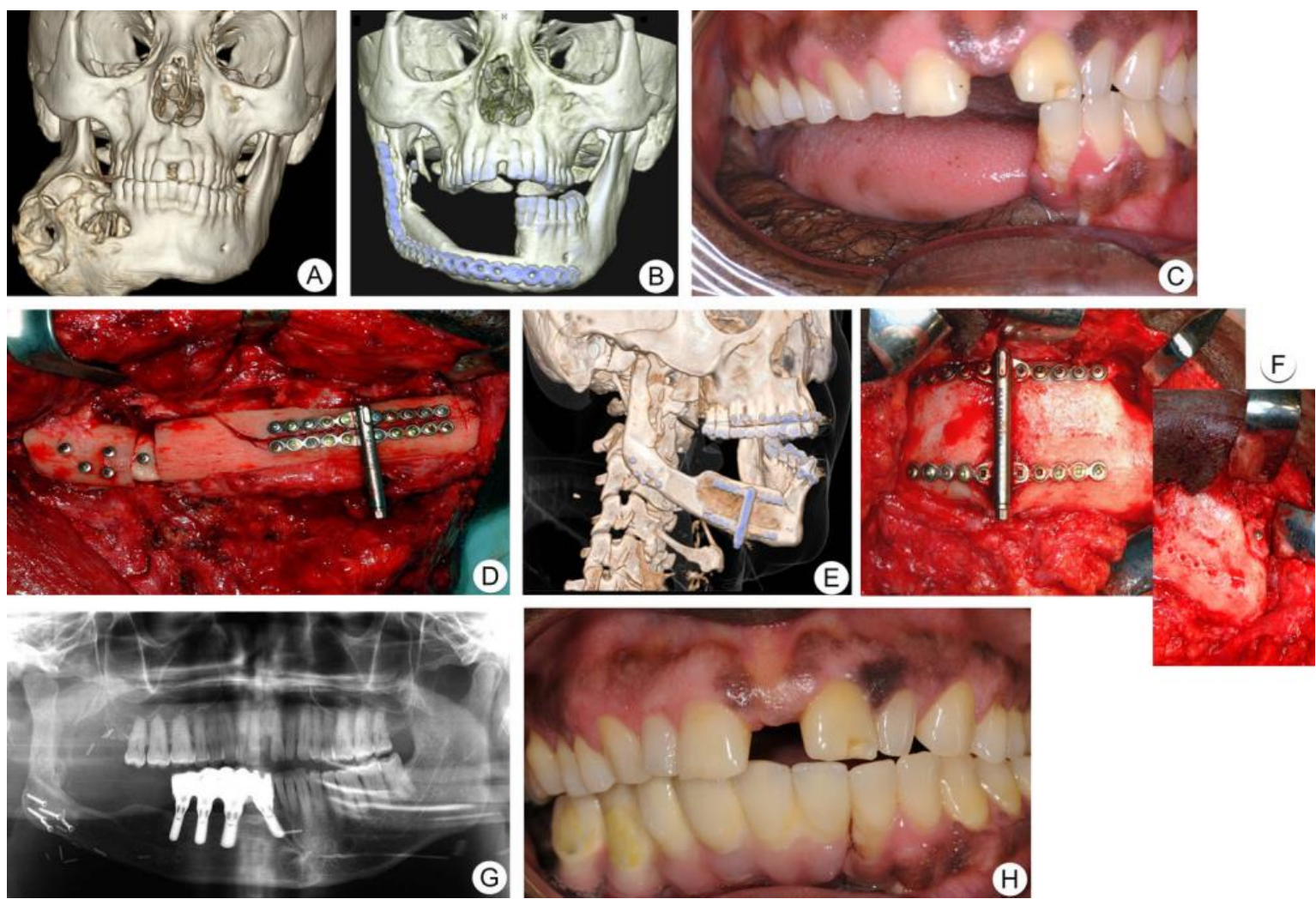

Fig. (2). Case 2. Patient with ameloblastic carcinoma. A. CT-scan 3D image of the tumor mass at the right side of the mandible. B. CT-scan 3D image of the right side of the mandible reconstructed with fibula bone. C. Clinical photograph showing inadequate mandible height. D. Clinical photograph showing the placement of the distraction device. E-F. CT-scan 3D image (E) and clinical photograph (F) showing excellent ossification between the mandible and the distracted segment, six months after the consolidation period. G. Implants placement at the right side of the mandible. H. Clinical photograph showing implant-supported bridge at the right side of the mandible.

After a latency period of 7 days, the superior segment was moved upward at a rate of $1 \mathrm{~mm} /$ day in two fractions of $0.5 \mathrm{~mm}$. This procedure was repeated for 14 days. Radiographic examination and clinical photographs at the end of the consolidation period confirmed that there was an excellent ossification between the mandible and the distracted segment (Figs. 2e \& f). Six months after the consolidation period, the distractor was removed, and the mandibular height in the area of interest for implant fixation had increased to around $31 \mathrm{~mm}$ and width unchanged at circa $11 \mathrm{~mm}$. Consequently, four implants were placed at the right side of the mandible (Fig. 2g). Prosthetic rehabilitation was performed after an osseointegration period of 4 months (Fig. 2h) and the patient was followed up for seven years. A high implant survival rate, with good patient satisfaction, was achieved with this therapy. 


\subsection{Case 3}

In 2014, a healthy 11-year-old girl of African origin was referred to the Department of Maxillofacial Surgery, Ryhov Hospital, Jönköping, Sweden, due to a cyst-like lesion measuring $11.5 \times 8.5 \mathrm{~mm}$ at the left side of the mandible. The intraoral radiograph showed a radiolucent lesion with a relatively well-defined margin between tooth 34 and 35 (Fig. 3a). No lining epithelium was found in the exposed cystic lesion at the time of surgery. Thus, radiological and surgical findings confirmed the diagnosis of Traumatic Bone Cyst (TBC). Moreover, six months later, a Cone-Beam Computed Tomography image (CBCT) showed a multicystic radiolucency measuring $28 \times 20 \mathrm{~mm}$ located at the left side of the mandible in the same place as the previous lesion (Fig. 3b). A biopsy was performed and the histological diagnosis revealed ameloblastoma. In August 2015, the patient was referred to the Department of Oral and Maxillofacial Surgery, Linköping University Hospital, Sweden for further treatment and rehabilitation.
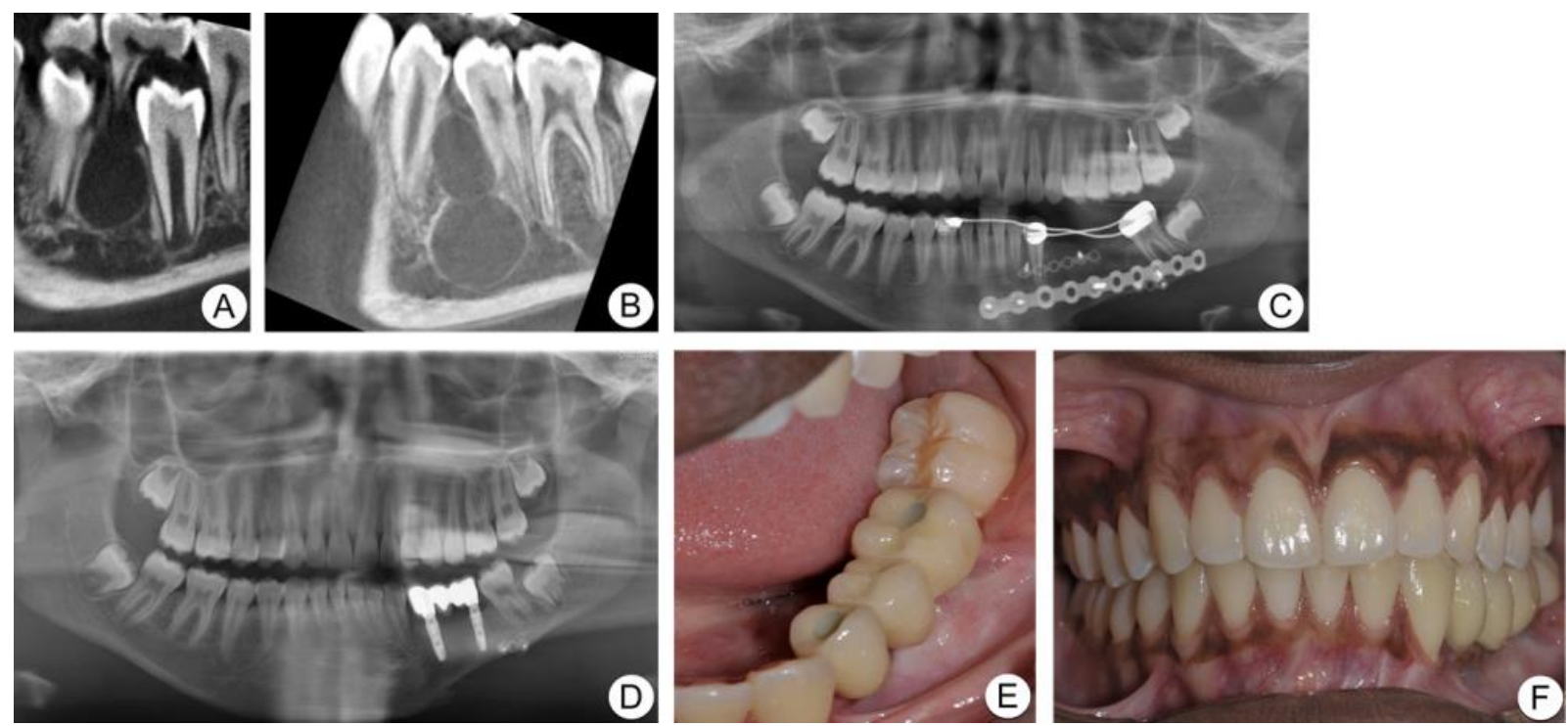

Fig. (3). Case 3. Patient with multicystic ameloblastoma. A. CBCT image showing a cystic lesion between tooth 34 and 35 . B. Six months postoperative control CBCT showing recurrence of multicystic lesion at the current location. C. Panoramic radiograph, three months after reconstruction with non-vascularized iliac bone graft at the left side of the mandible. D-F. One year postoperative panoramic radiograph (D) and clinical photographs (E \& F) showing implant-supported fixed prosthesis at the left side of the mandible.

A segmentary resection with an 8-mm safety margin and immediate reconstruction with nonvascularized iliac bone graft $(3 \times 2.5 \mathrm{~cm})$ and a titanium plate was performed (Fig. 3c). Twelve months later, the panoramic radiograph showed complete graft integration and the patient received two dental implants (Microthread ${ }^{\circledR}$ conical; OsseoSpeed, Mölndal, Sweden; $4.2 \mathrm{~mm}$ in diameter and $11 \mathrm{~mm}$ in length) to allow an implant-supported fixed complete prosthesis. At the oneyear follow-up post-implantation, no marginal bone loss was seen and the implant-supported prosthesis was functioning well with no signs of gingival pockets (Figs. 3d-f).

\section{DISCUSSION}

Ameloblastoma is a common odontogenic tumour, and the treatment of these tumours is highly debated. Ameloblastoma of the jaw is considered to have aggressive growth with a high rate of recurrence if not removed appropriately. The possible risk of recurrence thus explains the need for a long-term follow-up period. The most common clinical manifestation is swelling and/or pain [1, 2]. However, a variable proportion of cases have been diagnosed incidentally by routine radiographic examination [8]. Several strategies have been used for the treatment of ameloblastoma of the jaw, including surgical resection, conservative treatment, enucleation, and bone curettage [6, 9]. The importance of wide surgical resection to minimize the risk of recurrence has been discussed previously in the context of a randomized trial involving 48 patients [10]. Eleven of the 48 were initially treated with radical resection and none recurred. Twenty-two of the remaining 37 who were initially treated with conservative resection presented with recurrences. Sixteen of the 22 then had conservative secondary resections, which resulted in further recurrence in 6 
patients. The authors showed that initial radical resection is therefore superior to conservative management.

Although segmental osteotomies are recommended, this treatment has a high morbidity and affects the patient's quality of life. However, with immediate reconstruction of the jaw and prosthetic rehabilitation with dental implants there is a good chance of restoring the masticatory function and esthetics in these patients. In this case series, an 11year-old patient with ameloblastoma of the jaw underwent surgical osteotomies and reconstruction with nonvascularized iliac graft bone. Two dental implants were inserted in the grafted bone at the left side of the mandible. There were no signs of implant displacement after 18 months of radiographic follow-up (Fig. 3e). The treatment of ameloblastoma in children is complicated because of continuing facial growth, especially in the posterior mandible [11]. It has been suggested that there is a risk of dental implants becoming embedded or displaced as the jaw grows. However, this has not been studied in grafted bone in children.

Several other surgical interventions have been reported in the treatment of ameloblastoma, including enucleation and enucleation and curettage [12]. However, it is questionable why surgeons would choose these therapies with a high recurrence rate for aggressive neoplasms.

We have presented two cases of mandibular ameloblastoma with successful management involving bone resection and immediate reconstruction using DCIA and OFFF. Previous studies have shown no significant difference between these two surgical techniques regarding pain, morbidity, and quality of life [13, 14]. However, DCIA shows greater bone resorption with a remaining volume of $88 \%$ after 48 months, as compared to OFFF with $95 \%$ remaining volume after the same follow-up period [14].

One disadvantage of using the DCIA flap is the unnecessary bulk of the "obligatory muscle cuff" and abdominal subcutaneous fat, which makes it uncomfortable for the patient during the early healing phase [15 - 18]. However, the natural curvature and adequate bone height offer the possibility of exact reconstruction of the jaw. Thus, implant insertion may be easier and rehabilitation may be quicker.

\section{CONCLUSION}

Ameloblastoma is a locally aggressive neoplasm. In order to reduce the risk of recurrence, wide resection has been recommended. Immediate reconstruction with an iliac crest transplant is a favorable flap option. There is no need for volume-enhancing treatment prior to implant therapy. In addition, there is the added benefit of reduced rehabilitation time.

\section{ETHICS APPROVAL AND CONSENT TO PARTICIPATE}

The study was approved by the Regional Committee for Ethics in Linköping, Sweden (2015/415-31).

\section{HUMAN AND ANIMAL RIGHTS}

No Animals were used in this research. All human research procedures followed were in accordance with the ethical standards of the committee responsible for human experimentation (institutional and national), and with the Helsinki Declaration of 1975 , as revised in 2013.

\section{CONSENT FOR PUBLICATION}

Written informed consent was obtained from the patients for their anonymized information to be published in this article.

\section{CONFLICT OF INTEREST}

The authors declare no conflict of interest, financial or otherwise.

\section{ACKNOWLEDGEMENTS}

This study was supported by the Department of Oral and Maxillofacial Surgery, Linköping University Hospital, Linköping, Sweden.

\section{REFERENCES}

[1] Eckardt AM, Kokemüller H, Flemming P, Schultze A. Recurrent ameloblastoma following osseous reconstruction: A review of twenty years. J Craniomaxillofac Surg 2009; 37(1): 36-41. 
[http://dx.doi.org/10.1016/j.jcms.2008.07.009] [PMID: 19022680]

[2] Olaitan AA, Adeola DS, Adekeye EO. Ameloblastoma: Clinical features and management of 315 cases from Kaduna, Nigeria. J Craniomaxillofac Surg 1993; 21(8): 351-5. [http://dx.doi.org/10.1016/S1010-5182(05)80497-4] [PMID: 8113429]

[3] Pathology \& Genetics. Eds, Barnes L, Eveson JW, Reichart P, Sidransky D. WHO Classification of Tumours, $3^{\text {rd }}$ ed. Head And Neck Tumours 2005; 9: 978-92-832-2417-4.

[4] Hall BE, Zhang L, Sun ZJ, et al. Conditional TNF- $\alpha$ overexpression in the tooth and alveolar bone results in painful pulpitis and osteitis. J Dent Res 2016; 95(2): 188-95

[http://dx.doi.org/10.1177/0022034515612022] [PMID: 26503912]

[5] Shear M, Singh S. Age-standardized incidence rates of ameloblastoma and dentigerous cyst on the Witwatersrand, South Africa. Community Dent Oral Epidemiol 1978; 6(4): 195-9. [http://dx.doi.org/10.1111/j.1600-0528.1978.tb01149.x] [PMID: 278703]

[6] Olaitan AA, Adeola DS, Adekeye EO. Ameloblastoma: Clinical features and management of 315 cases from Kaduna, Nigeria. J Craniomaxillofac Surg 1993; 21(8): 351-5. [http://dx.doi.org/10.1016/S1010-5182(05)80497-4] [PMID: 8113429]

[7] Santos TdeS, Piva MR, Andrade ES, Vajgel A, Vasconcelos RJ, Martins-Filho PR. Ameloblastoma in the Northeast region of Brazil: A review of 112 cases. J Oral Maxillofac Pathol 2014; 18(Suppl. 1): S66-71. [http://dx.doi.org/10.4103/0973-029X.141368] [PMID: 25364183]

[8] Konouchi H, Asaumi J, Yanagi Y, et al. Usefulness of contrast enhanced-MRI in the diagnosis of unicystic ameloblastoma. Oral Oncol 2006; 42(5): 481-6 [http://dx.doi.org/10.1016/j.oraloncology.2005.10.001] [PMID: 16488178]

[9] Hammarfjord O, Roslund J, Abrahamsson P, et al. Surgical treatment of recurring ameloblastoma, are there options? Br J Oral Maxillofac Surg 2013; 51: e762-766.

[http://dx.doi.org/10.1016/j.bjoms.2013.08.013]

[10] Pogrel MA, Montes DM. Is there a role for enucleation in the management of ameloblastoma? Int J Oral Maxillofac Surg 2009; 38(8): 807-12.

[http://dx.doi.org/10.1016/j.ijom.2009.02.018] [PMID: 19297131]

[11] Apajalahti S, Kelppe J, Kontio R, Hagström J. Imaging characteristics of ameloblastomas and diagnostic value of computed tomography and magnetic resonance imaging in a series of 26 patients. Oral Surg Oral Med Oral Pathol Oral Radiol 2015; 120(2): e118-30. [http://dx.doi.org/10.1016/j.oooo.2015.05.002] [PMID: 26166034]

[12] Reichart PA, Philipsen HA. Desmoplastic Ameloblastoma: Odontogenic tumors and allied lesions. London: Quintessence Publishing Co Ltd 2004; pp. 69-76.

[13] Hammarfjord O, Roslund J, Abrahamsson P, et al. Surgical treatment of recurring ameloblastoma, are there options? Br J Oral Maxillofac Surg 2013; 51(8): 762-6

[http://dx.doi.org/10.1016/j.bjoms.2013.08.013] [PMID: 24050920]

[14] Cronin RJ, Oesterle LJ. Implants use in growing patients. Dint Clin North AM 1998; 42: 1-35.

[15] Carlson ER, Marx RE. The ameloblastoma: Primary, curative surgical management. J Oral Maxillofac Surg 2006; 64(3): 484-94. [http://dx.doi.org/10.1016/j.joms.2005.11.032] [PMID: 16487813]

[16] Hong J, Yun PY, Chung IH, et al. Long-term follow up on recurrence of 305 ameloblastoma cases. Int J Oral Maxillofac Surg 2007; 36(4): 283-8. [http://dx.doi.org/10.1016/j.ijom.2006.11.003] [PMID: 17222535]

[17] Wilkman T, Apajalahti S, Wilkman E, et al. A comparison of bone resorption over time: An analysis of the free scapular, iliac crest, and fibular microvascular flaps in mandibular reconstruction. J Oral Maxillofac Surg 2017; 75(3): 616-21. [http://dx.doi.org/10.1016/j.joms.2016.09.009] [PMID: 27725102]

[18] Möhlhenrich SC, Kniha K, Elvers D, et al. Intraosseous stability of dental implants in free revascularized fibula and iliac crest bone flaps. J Craniomaxillofac Surg 2016; 44(12): 1935-9.

[http://dx.doi.org/10.1016/j.jcms.2016.09.011] [PMID: 27769721]

(C) 2018 Shiva et al.

This is an open access article distributed under the terms of the Creative Commons Attribution 4.0 International Public License (CC-BY 4.0), a copy of which is available at: https://creativecommons.org/licenses/by/4.0/legalcode. This license permits unrestricted use, distribution, and reproduction in any medium, provided the original author and source are credited. 